\title{
Electrogenic Sodium Absorption in Rabbit Cecum In Vitro
}

\author{
Joseph H. Sellin, Hector Oyarzabal, and Edward J. Cragoe \\ University of Texas Medical School at Houston, Division of Gastroenterology, Department of Internal Medicine, Houston, Texas \\ 77225; and Merck, Sharp \& Dohme Research Laboratories, West Point, Pennsylvania 19446
}

\begin{abstract}
Regional variations in the ion transport properties of the colon may have significant physiological and pathophysiological implications. However, only limited studies have been performed in cecum, which comprises $50 \%$ of the macrosurface of the rabbit colon. In vitro under short-circuit conditions, cecum actively absorbed $\mathrm{Na}$ and $\mathrm{Cl}\left(J_{\text {net }}^{\mathrm{Na}}=5.6 \pm 0.3, J_{\text {net }}^{\mathrm{Cl}}=1.5 \pm 0.3\right.$ $\left.\mu \mathrm{eq} \cdot \mathrm{cm}^{-2} \cdot \mathrm{h}^{-1}\right)$ with a short-circuit current $\left(I_{\mathrm{sc}}\right)$ of $6.29 \pm 0.2$ $\mu \mathrm{eq} \cdot \mathrm{cm}^{-2} \cdot \mathrm{h}^{-1}$. Cl substitution with sulfate decreased both $J_{\text {net }}^{\mathrm{Na}}$ and $I_{\mathrm{sc}}$ by $1.3 \mu \mathrm{eq} / \mathrm{cm}^{2} \cdot \mathrm{h}^{-1} . \mathrm{HCO}_{3}$ removal decreased both $J_{\text {net }}^{\mathrm{Na}}$ and $I_{\mathrm{sc}} 3.3 \mu \mathrm{eq} \cdot \mathrm{cm}^{-2} \cdot \mathrm{h}^{-1}$. This effect was due primarily to removal of serosal $\mathrm{HCO}_{3}$. There was both a linear correlation between $J_{\text {net }}^{\mathrm{Na}}$ and $I_{\mathrm{sc}}(r=0.845)$ and a concentration-dependent stimulation of $I_{s c}$ by increasing [Na] in the bathing media. However, $10^{-4} \mathrm{M}$ amiloride did not significantly alter either $I_{\mathrm{sc}}$ or $J_{\text {net }}^{\mathrm{Na}}$. In contrast, $1^{-4} \mathrm{M}$ phenamil, an amiloride analogue highly specific for the Na channel, significantly blocked both $I_{\mathrm{sc}}$ and $J_{\text {net }}^{\mathrm{Na}}$. The sulfhydryl reagent PCMBS increased $I_{\mathrm{sc}}$; this response was reversed by phenamil. Electrogenic $\mathrm{Cl}$ secretion was stimulated by $1 \mathrm{mM}$ theophylline, $10^{-4} \mathrm{M} 8 \mathrm{BrcAMP}$ and $10^{-4}$ M 8BrcGMP. None of the secretagogues inhibited $J_{\text {net }}^{\mathrm{Na}}$. Epinephrine $(5.5 \mu \mathrm{M})$ increased $J_{\text {net }}^{\mathrm{Na}}$ from $5.9 \pm 1.3$ to $7.8 \pm 1.1$ $(P=0.02)$ and $J_{\text {net }}^{\mathrm{Cl}}$ from $0.1 \pm 1.2$ to $2.0 \pm 0.8$ ( $P$ NS) $\mu \mathrm{eq} \cdot \mathrm{cm}^{-2} \cdot \mathrm{h}^{-1}$. Studies of $\mathrm{pH}$ stat demonstrated an epinephrine-stimulated increase in $J_{\mathrm{m}-\mathrm{s}}^{\mathrm{HCO}_{3}}$ without a change in $J_{\mathrm{s}-\mathrm{m}}^{\mathrm{HCO}}$. Thus, cecum exhibits a distinct type of electrogenic Na electrogenic $\mathrm{Na}$ absorption which is partially dependent on the presence of $\mathrm{Cl}$ and $\mathrm{HCO}_{3}$, not blocked by amiloride but by phenamil. Because of its large surface area and its novel mechanism of electrogenic $\mathrm{Na}$ transport, the cecum exerts an important regulatory role in colonic fluid and electrolyte balance.
\end{abstract}

\section{Introduction}

Segmental heterogeneity of intestinal epithelial electrolyte transport may underlie important functional differences and provide insight into the integrative function of the gut. Recent studies from our laboratory and others have established that there are important differences between the proximal and distal colon (1-4). Additionally, there now appear to be differences within the rabbit proximal colon between the segment immediately distal to the cecum (the triple haustrated segment) and the region $10 \mathrm{~cm}$ beyond the cecum (the single haustrated segment) $(4,5)$.

The cecum's transport function, however, has remained largely uninvestigated. Limited studies have suggested that the

Received for publication 11 February 1987 and in revised form 26 October 1987.

J. Clin. Invest.

(c) The American Society for Clinical Investigation, Inc. 0021-9738/88/04/1275/09 \$2.00

Volume 81, April 1988, 1275-1283 cecum absorbs $\mathrm{Na}$ efficiently $(4,6)$. In the present study, we characterize in detail the ion transport characteristics of rabbit cecum in vitro.

Cecal transport is dominated by electrogenic $\mathrm{Na}$ transport that is not readily inhibited by amiloride. However, the amiloride analogue phenamil has a significant inhibitory effect. $\mathrm{Na}$ absorption is not obviously coupled to $\mathrm{Cl}$ or $\mathrm{HCO}_{3}$, but is somewhat dependent on the presence of both anions. Electrogenic $\mathrm{Cl}$ secretion can be stimulated by both cAMP and cGMP-mediated secretagogues, but there is no inhibition of electroneutral $\mathrm{NaCl}$ absorption. Epinephrine elicits both electroneutral $\mathrm{Na}$ absorption and $\mathrm{HCO}_{3}$ absorption. Given the $\mathrm{Na}$ absorptive capacity and relatively large surface area of the cecum, this colonic segment plays an important role in intestinal fluid and electrolyte balance.

\section{Methods}

Experimental protocol. New Zealand White male rabbits $(2-3 \mathrm{~kg})$ fed with standard rabbit laboratory diet and water ad libitum were killed during the soft feces period with an i.v. injection $(3.0 \mathrm{ml} / \mathrm{kg}$ rabbit $)$ of enthanasia solution T6 in an ear marginal vein. ( $N$-[2-(M-methoxyphenyl)-2 ethyl-butyl-(1)]-gamma hydroxy butyramide, $200 \mathrm{mg} / \mathrm{ml}$; 4,4' methylene-bis(cycholexyl)trimethyl-ammonium iodide), 50 $\mathrm{mg} / \mathrm{ml}$; tetracaine $\mathrm{HCl}, 5 \mathrm{mg} / \mathrm{ml}, 0.6 \mathrm{ml}$ dimethylformamide). A $10-\mathrm{cm}$ segment of cecum between the appendix and the ileo-cecal valve was rapidly excised, opened along its mesenteric border, and rinsed several times in an ice-cold bathing solution gassed with $95 \%$ $\mathrm{O}_{2}, 5 \% \mathrm{CO}_{2}$, until its surface was clear of feces. The segment was then placed serosa side up on a plexiglass plate; transverse incisions were made on every other colonic haustra with a razor blade. Two-haustrated small segments were returned rapidly to the bubbled solution. The serosa and outer layer were dissected with a fine forcep from each one of the two-haustrated segments.

Ringer standard solutions used in these experiments contained (in mmol/liter): $\mathrm{NaCl}, 114 ; \mathrm{KCl}, 5 ; \mathrm{Na} \mathrm{H}_{2} \mathrm{PO}_{4}, 0.30 ; \mathrm{NaHPO}_{4}, 1.65$; $\mathrm{CaCl}_{2}, 1.25 ; \mathrm{MgCl}_{2}, 1.1 ; \mathrm{NaHCO}_{3}, 25 ;$ glucose, 10. Either choline or lithium replaced $\mathrm{Na}$ in $\mathrm{Na}$-free solutions; sulfate and mannitol replaced chloride. $\mathrm{HCO}_{3}$-free solutions had $5 \mathrm{mM}$ Hepes as a substitute buffer.

Transepithelial electrical potential difference (PD), ${ }^{1}$ total conductance $\left(G_{t}\right)$, and short-circuit current $\left(I_{\mathrm{sc}}\right)$ were measured as described previously (1). Pieces of intestinal mucosa were mounted in Ussing chambers $\left(1.12 \mathrm{~cm}^{2}\right.$ of exposed surface area) and bathed with $10 \mathrm{ml}$ of standard Ringer's solution on each side. Solutions were circulated by gas lift and maintained at $37^{\circ} \mathrm{C}$ in water-jacketed reservoirs. In $\mathrm{HCO}_{3}$ buffered solutions, $95 \% \mathrm{O}_{2} / 5 \% \mathrm{CO}_{2}$ was employed; in $\mathrm{HCO}_{3}$-free experiments, $100 \% \mathrm{O}_{2}$ was used.

Ion fluxes were measured over two successive periods. Tissues from the same rabbit were mounted for $45 \mathrm{~min}$ before ${ }^{22} \mathrm{Na}$ and ${ }^{36} \mathrm{Cl}$ were added together to either the mucosal or serosal reservoirs, and the

1. Abbreviations used in this paper: 8BrcAMP, 8-bromo-cAMP; 8BrcGMP, 8-bromo-cGMP; $G_{\mathrm{t}}$, total conductance; $I_{\mathrm{sc}}$, short-circuit current; $J_{\mathrm{m}-\mathrm{s}}, J_{\mathrm{s}-\mathrm{m}}$, mucosal-to-serosal and serosal-to-mucosal fluxes; PCMBS, $P$-hydroxymercuribenzoate sodium; PD, potential difference. 
tissues were short-circuited by voltage clamping. Tissues were paired by matching resistances. If at any time during flux measurements the resistances of paired tissues differed by $>25 \%$, the experiment was rejected. The initial flux (period 1) lasted $30 \mathrm{~min}$; after a 20-min equilibration period, a second flux measurement was made over a 40-min period (period II). Test substances were added 10-15 min before a flux period, depending on the protocol of the individual experiment. Electrical responses were assessed during the $15 \mathrm{~min}$ after addition of a specific agent when fluxes were not performed.

Unidirectional mucosal-to-serosal and serosal-to-mucosal fluxes $\left(J_{\mathrm{m}-\mathrm{s}}\right.$ and $\left.J_{\mathrm{s}-\mathrm{m}}\right)$ and the net fluxes $\left(J_{\mathrm{net}}\right)$ of $\mathrm{Na}, \mathrm{K}$, and $\mathrm{Cl}$ were calculated from aliquots taken at the beginning and end of each flux period. To calculate the unidirectional ion fluxes, we divided the steady-state rates of radioisotope transfer by the specific activity of the initially labeled side and by the surface area of exposed tissue. The net flux is calculated as the difference between oppositely directed unidirectional fluxes of tissue pairs $\left(J_{\text {net }}=J_{\mathrm{m}-\mathrm{s}}-J_{\mathrm{s}-\mathrm{m}}\right)$. From these measurements, the residual ion flux $\left(J^{\mathrm{R}}=I_{\mathrm{sc}}-J_{\mathrm{net}}^{\mathrm{Na}}+J_{\mathrm{net}}^{\mathrm{a}}\right)$, which represents that part of the $I_{\mathrm{sc}}$ not attributable to the movement of $\mathrm{Na}$ or $\mathrm{Cl}$, was calculated.

pH stat experiments. Two segments of stripped cecal mucosa were mounted in Ussing chambers; the transepithelial electrical potential difference referenced to the serosal bathing solution, $I_{\mathbf{s c}}$, and conductance $\left(G_{t}\right)$ were determined. Rates of luminal acidification/alkalinization $\left(J_{s-m}\right)$ were determined by using the $\mathrm{HCO}_{3}$-Ringer's as the serosal solution and a Ringer's solution in which all bicarbonate and phosphates were replaced with $28 \mathrm{mM}$ Na-gluconate and $1 \mathrm{mM}$ Hepes in the mucosal reservoir. The serosal solution was gassed with $95 \% \mathrm{O}_{2} / 5 \%$ $\mathrm{CO}_{2}$ and, at $37^{\circ} \mathrm{C}$, had a $\mathrm{pH}$ of 7.4. The mucosal solution was gassed with $100 \% \mathrm{O}_{2}$ which passed through an Ascarite II $\mathrm{CO}_{2}$ trap (Thomas Scientific, Swedesboro, NJ) and pH was maintained constant at pH 7.4 with a pH stat apparatus (Radiometer, Copenhagen, Denmark) under short-circuit conditions. The titrants used were $0.01 \mathrm{~N} \mathrm{HCl}$ or $\mathrm{NaOH}$ in phosphate-bicarbonate-free Ringer's previously described.

Rates of serosal $\left(J_{\mathrm{m}-\mathrm{s}}\right)$ acidification/alkalinization were determined by mounting tissues with the serosal surface bathed in the phosphatebicarbonate-free Ringer's and the mucosal surface bathed with standard $\mathrm{HCO}_{3}$-Ringer's. After the tissues had stabilized electrically, rates of acidification/alkalinization were determined over a 30-60-min period.

The effects of epinephrine on acidification/alkalinization were studied on both mucosal and serosal surfaces of the rabbit cecum as follows: (a) tissues were mounted in vitro and allowed to reach an electrical steady state; (b) a control (period I) flux of 30-40 min was measured; and $(c)$ epinephrine adjusted to pH 7.4 (ESI Pharmaceuticals, Elkins-Sinn, Inc., Cherry Hill, NJ) was added to produce a final concentration of $5.5 \times 10^{-5} \mathrm{M}$ (period II). The period II flux was measured for 30-40 min. This procedure was followed for both $\mathrm{m}-\mathrm{s}$ and s-m flux measurements.

Although we cannot definitely determine the ionic species respon- sible for changes in $\mathrm{pH}$, we have arbitrarily decided to express such changes as $J^{\mathrm{HCO}_{3}}$ (in $\mu \mathrm{eq} \cdot \mathrm{cm}^{-2} \cdot \mathrm{h}^{-1}$ ). $J^{\mathrm{HCO}}$ was calculated from the amount of titrant added over time. We observed a slow drift in $\mathrm{pH}$ of the $\mathrm{pH}$ stat solution without tissue $\left(-0.62 \pm 0.31 \mu \mathrm{eq} \cdot \mathrm{cm}^{-2} \cdot \mathrm{h}^{-1}, n\right.$ $=16$ ). Therefore, the baseline drift of the $\mathrm{pH}$ stat solution was determined before and after the experiment. The drift was substracted from the measured rate of acidification/alkalinization to determine calculated rate of $\mathrm{HCO}_{3}$ movement of the tissue.

Statistics. Student's paired $t$ test was used for pair-matched controls in the same animal. Otherwise, Student's unpaired $t$ test was employed, except for Table I in which analysis of variance and the Tukey multiple comparison test were employed.

Materials. Epinephrine was obtained from Elkins-Sinn, Inc. (Cherry Hill, NJ). $P$-hydroxymercuribenzoate sodium salt, theophylline, 8BrcAMP, and 8BrcGMP were obtained from Sigma Chemical Co. (St. Louis, MO). Amiloride, phenamil, 5-( $N$-prophyl- $N$-butyl)-2',4' dichlorobenzamil, 5-[N-(4-chlorobenzyl)-2',4'-dimethyl-benzamil, and 2'4'-dimethylbenzamil were synthesized by previously established methods $(7,8) .{ }^{22} \mathrm{Na}$ and ${ }^{42} \mathrm{~K}$ were obtained from New England $\mathrm{Nu}$ clear (Boston, MA); ${ }^{36} \mathrm{Cl}$ from ICN Pharmaceuticals (Cleveland, $\mathrm{OH}$ ).

\section{Results}

Basal ion transport. In vitro rabbit cecum, bathed in normal Ringer's, exhibited a reproducible and characteristic set of transport parameters. There was a significant, serosa-positive $I_{\mathrm{sc}}, 6.29 \pm 0.20 \mu \mathrm{eq} \cdot \mathrm{cm}^{-2} \cdot \mathrm{h}^{-1}$. This $I_{\mathrm{sc}}$ is higher than the basal $I_{\mathrm{sc}}$ found in small intestine (9), proximal colon (1), or distal colon (10) implying significant electrogenic ion transport. The conductance of $7.0 \pm 0.3 \mathrm{mS} \cdot \mathrm{cm}^{-2}$ is somewhat higher than that of distal colon but lower than that found in proximal colon $(1,10)$, indicating that the cecum is a moderately "tight" epithelium. Ion fluxes demonstrate that the cecum absorbs $\mathrm{Na}$ actively at a higher rate than other intestinal segments (Table I). $\mathrm{Cl}$ is absorbed at a much lower rate $(1.5 \pm 0.3$ $\left.\mu \mathrm{eq} \cdot \mathrm{cm}^{-2} \cdot \mathrm{h}^{-1}\right)$ and there is a significant residual ion flux. $J_{\text {net }}^{\mathrm{Na}}$ equals $89 \%$ of basal $I_{s c}$. This pattern of ion fluxes is similar to distal colon, in which electrogenic $\mathrm{Na}$ absorption accounts for $I_{\mathrm{sc}}$ and anion transport is mediated primarily by electroneutral $\mathrm{Cl}-\mathrm{HCO}_{3}$ exchange (10).

To determine whether the epithelium in vitro was stable over time, successive flux periods were performed (Table II). There was a significant increase in conductance of $2.7 \pm 0.9$ $\mathrm{mS} \cdot \mathrm{cm}^{-2}(P=0.027)$. This was reflected in a trend of increased unidirectional fluxes of both $\mathrm{Na}$ and $\mathrm{Cl}$. However,

Table I. Basal Ion Transport Parameters in Rabbit Cecum

\begin{tabular}{|c|c|c|c|c|c|c|c|c|c|}
\hline \multirow[b]{2}{*}{ Group } & \multicolumn{3}{|c|}{$J^{\mathrm{Na}}$} & \multicolumn{3}{|c|}{ ja } & \multirow[b]{2}{*}{$I_{\mathbf{c}}$} & \multirow[b]{2}{*}{$J^{\mathbf{R}}$} & \multirow[b]{2}{*}{$G_{\mathrm{t}}$} \\
\hline & m-s & s-m & net & m-s & s-m & net & & & \\
\hline & \multicolumn{8}{|c|}{$\mu e q \cdot \mathrm{cm}^{-2} \cdot \mathrm{h}^{-1}$} & $\mathrm{mS} \cdot \mathrm{cm}^{-2}$ \\
\hline A. Normal Ringer's (41) & $9.2 \pm 0.4$ & $3.6 \pm 0.2$ & $5.6 \pm 0.3$ & $8.2 \pm 0.4$ & $6.7 \pm 0.3$ & $1.5 \pm 0.3$ & $6.29 \pm 0.2$ & $2.2 \pm 0.4$ & $7.0 \pm 0.3$ \\
\hline B. Cl-free (9) & $6.6 \pm 0.8^{*}$ & $2.2 \pm 02^{*}$ & $4.4 \pm 0.7$ & - & - & - & $4.80 \pm 0.5^{*}$ & $0.5 \pm 0.5$ & $3.8 \pm 0.5^{*}$ \\
\hline C. $\mathrm{HCO}_{3}$-free (9) & $4.5 \pm 0.4^{*}$ & $2.4 \pm 0.4^{*}$ & $2.1 \pm 0.3^{* \ddagger}$ & $7.1 \pm 0.5$ & $7.6 \pm 0.5$ & $-0.5 \pm 0.6^{*}$ & $3.11 \pm 0.3^{* \pm}$ & $0.5 \pm 0.6$ & $5.8 \pm 0.6^{* \pm}$ \\
\hline D. NA-free choline (8) & - & - & - & $8.1 \pm 0.6$ & $7.6 \pm 0.5$ & $0.5 \pm 0.6$ & $1.11 \pm 0.29^{* \neq \S}$ & $1.5 \pm 0.7$ & $9.7 \pm 0.7$ \\
\hline E. Na-free lithium (4) & - & - & - & ND & ND & ND & $0.26 \pm 0.02$ & ND & $15.7 \pm 3.6^{* \pm 8}$ \\
\hline
\end{tabular}

Composition of solutions is described in Methods. Number of subjects given in parentheses. ${ }^{*} P<0.05$, compared with group A. ${ }^{\ddagger} P<0.05$ compared with group B. ${ }^{\$} P<0.05$ compared with group C, using Tukey multiple comparison procedure. ND, not done. 


\begin{tabular}{|c|c|c|c|c|c|c|c|c|c|}
\hline Group & \multicolumn{3}{|c|}{$J^{\mathrm{Na}}$} & \multicolumn{3}{|c|}{$\mathrm{ja}^{\mathrm{a}}$} & $I_{x}$ & $J^{\mathbf{R}}$ & $G_{\mathrm{t}}$ \\
\hline & \multicolumn{8}{|c|}{$\mu e q \cdot \mathrm{cm}^{-2} \cdot \mathrm{h}^{-1}$} & $\mathrm{mS} \cdot \mathrm{cm}^{-2}$ \\
\hline I Control & $8.1 \pm 0.4$ & $3.2 \pm 0.4$ & $4.9 \pm 0.4$ & $6.3 \pm 0.4$ & $5.1 \pm 0.4$ & $1.2 \pm 0.5$ & $5.94 \pm 0.49$ & $2.2 \pm 0.5$ & $6.8 \pm 0.5$ \\
\hline II Control & $8.9 \pm 0.7$ & $3.7 \pm 0.4$ & $5.3 \pm 0.4$ & $6.9 \pm 0.5$ & $6.2 \pm 0.6$ & $0.7 \pm 0.5$ & $6.36 \pm 0.49$ & $1.8 \pm 0.4$ & $9.3 \pm 1.5^{*}$ \\
\hline
\end{tabular}

Results are given for eight animals. The protocol for these studies involved an initial basal flux measurement over 30 min (I Control), a 20 -min stabilization and a second flux period of $40 \mathrm{~min}$ (II Control). ${ }^{*} P<0.05$ vs. control.

there was neither a significant change in fluxes nor in $I_{\mathrm{sc}}$ between the two periods. Thus the transport parameters are stable (save for $G_{t}$ ) for the $150-180$ minutes required for in vitro flux studies.

Ion substitutions. To further elucidate the mechanisms of cecal ion transport, flux studies were performed in $\mathrm{Na}$-free Ringer's, Cl-free sulfate Ringer's, and bicarbonate-free, Hepes-buffered Ringer's solution.

We employed two Na-free solutions with either choline or lithium substitution. In the lithium-substituted Ringer's, there was a minimal $I_{\mathrm{sc}}, 0.27 \pm 0.02 \mu \mathrm{eq} \cdot \mathrm{cm}^{-2} \cdot \mathrm{h}^{-1}$. In the cholineRinger's, the $I_{\mathrm{sc}}$ was decreased from that in normal Ringer's $\left(1.11 \pm 0.29 \mu \mathrm{eq} \cdot \mathrm{cm}^{-2} \cdot \mathrm{h}^{-1}\right)$, but somewhat higher than in the lithium-containing solutions. The explanation for this difference is not readily apparent. In the choline-containing Ringer's, there was no significant $\mathrm{Cl}$ net movement.

Under Cl-free conditions, $I_{\mathrm{sc}}$ was $4.80 \pm 0.5 \mu \mathrm{eq} \cdot \mathrm{cm}^{-2} \cdot \mathrm{h}^{-1}$, significantly less than that in normal Ringer's. $J_{\text {net }}^{\mathrm{Na}}$ was $4.4 \pm 0.7$ $\mu \mathrm{eq} \cdot \mathrm{cm}^{-2} \cdot \mathrm{h}^{-1}$, also reduced when compared to normal Ringer's. The lower $G_{t}$ found in the $\mathrm{Cl}$-free solution (3.8 \pm 0.5 $\mathrm{mS} \cdot \mathrm{cm}^{-2}$ ) suggests that there is a major $\mathrm{Cl}$ conductance in the cecum.

In bicarbonate-free Ringer's, $I_{\mathrm{sc}}$ was $3.11 \pm 0.31$ $\mu \mathrm{eq} \cdot \mathrm{cm}^{-2} \cdot \mathrm{h}^{-1}$, significantly less than that in normal Ringer's. $J_{\text {net }}^{\mathrm{Na}}$ under these conditions was $2.1 \pm 0.3 \mu \mathrm{eq} \cdot \mathrm{cm}^{-2} \cdot \mathrm{h}^{-1}$, while $\mathrm{Cl}$ transport was essentially nil $\left(-0.5 \pm 0.6 \mu \mathrm{eq} \cdot \mathrm{cm}^{-2} \cdot \mathrm{h}^{-1}\right)$. The conductance of $5.8 \pm 0.6 \mathrm{mS} \cdot \mathrm{cm}^{-2}$ was similar to that in normal Ringer's.

Anions clearly have an important role in regulating $\mathrm{Na}$ transport in rabbit cecum. In Cl-free Ringer's, $J_{\text {net }}^{\mathrm{Na}}$ is reduced

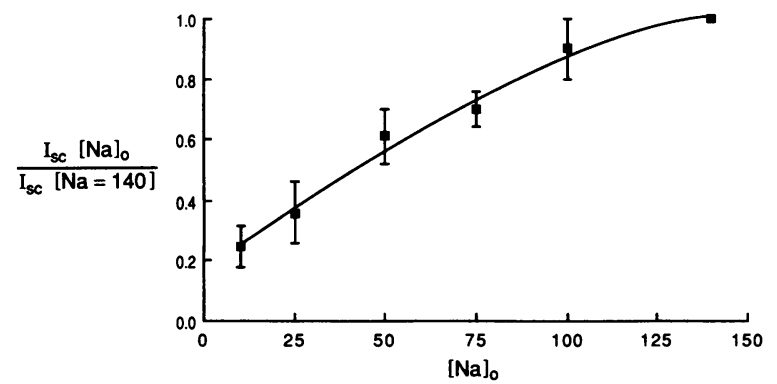

Figure 1. $I_{\mathrm{sc}}$ response to increasing $[\mathrm{Na}]_{\mathrm{o}}$. As $[\mathrm{Na}]$ in the fluid bathing rabbit cecum is increased from 10 to 140 ( $x$-axis), there is a corresponding increase in $I_{\mathrm{sc}} . I_{\mathrm{sc}}\left[\mathrm{Na}_{0}\right] / I_{\mathrm{sc}}\left[\mathrm{Na}_{0}=140\right]$ represents the ratio of current at a particular [Na $]_{0}$ to pair-matched controls exposed to $140 \mathrm{mM}[\mathrm{Na}] . n[\mathrm{Na}=10] 4 ;[\mathrm{Na}=25] 4 ;[\mathrm{Na}=50] 6 ;[\mathrm{Na}=75] 4 ;$ $[\mathrm{Na}=100] 3 ;[\mathrm{Na}=140] 12$. by $1.2 \mu \mathrm{eq} \cdot \mathrm{cm}^{-2} \cdot \mathrm{h}^{-1}$ while in $\mathrm{HCO}_{3}$-free Ringer's it is decreased by $3.5 \mu \mathrm{eq} \cdot \mathrm{cm}^{-2} \cdot \mathrm{h}^{-1}$. This may represent either anion-coupled or anion-dependent $\mathrm{Na}$ absorption. In $\mathrm{HCO}_{3}-$ free solutions, $J_{\text {net }}^{\mathrm{C}}$ is significantly less than in normal Ringer's $\left(-0.5 \pm 0.6\right.$ vs. $\left.1.5 \pm 0.3 \mu \mathrm{eq} \cdot \mathrm{cm}^{-2} \cdot \mathrm{h}^{-1}, P<0.05\right)$. However, this change $\left(-2.0 \mu \mathrm{eq} \cdot \mathrm{cm}^{-2} \cdot \mathrm{h}^{-1}\right)$ is equivalent to the change in $J^{\mathrm{R}}\left(-1.7 \mu \mathrm{eq} \cdot \mathrm{cm}^{-2} \cdot \mathrm{h}^{-1}\right)$ rather than the change in $J_{\text {net }}^{\mathrm{Na}}$ $\left(-3.5 \mu \mathrm{eq} \cdot \mathrm{cm}^{-2} \cdot \mathrm{h}^{-1}\right)$. Additionally, the decrease in $I_{\mathrm{sc}}(3.2$ $\mu$ eq $\cdot \mathrm{cm}^{-2} \cdot \mathrm{h}^{-1}$ ) is roughly equal to the decrease in $J_{\text {net }}^{\mathrm{Na}}$ under these conditions. Thus, changes in $\mathrm{Cl}$ transport appear to be linked to changes in residual ion flux while changes in $\mathrm{Na}$ absorption are reflected by changes in $I_{\text {sc }}$.

We examined the effect of changing [Na] in the bathing media $\left([\mathrm{Na}]_{0}\right)$ on $I_{\mathrm{sc}}$. In these experiments, chloride was maintained at $121 \mathrm{mM}$ with choline substituted for $\mathrm{Na}$ (Fig. 1). There is a definite, concentration-dependent effect of $[\mathrm{Na}]_{0}$ on $I_{\text {sc }}$. Interestingly, there is minimal, if any, saturation until $[\mathrm{Na}]_{0}$ reaches $100 \mathrm{mM}$. These studies establish that $I_{\mathrm{sc}}$ in cecum is a function of $[\mathrm{Na}]_{0}$.

To further explore the link between $J_{\text {net }}^{\mathrm{Na}}$ and $I_{\mathrm{sc}}$, we examined the relation between $J_{\text {net }}^{\mathrm{Na}}$ and $I_{\mathrm{sc}}$ of individual experiments in the various Ringer's solutions (Fig. 2). It is readily apparent that there is a strong correlation between $J_{\text {net }}^{\mathrm{Na}}$ and $I_{\mathrm{sc}}$ as $\mathrm{Na}$ absorption varies over a wide range of values. Therefore, it appears that $\mathrm{Na}$ absorption in the cecum is electrogenic.

Effect of amiloride. The diuretic amiloride inhibits electrogenic $\mathrm{Na}$ absorption in a wide variety of epithelia including

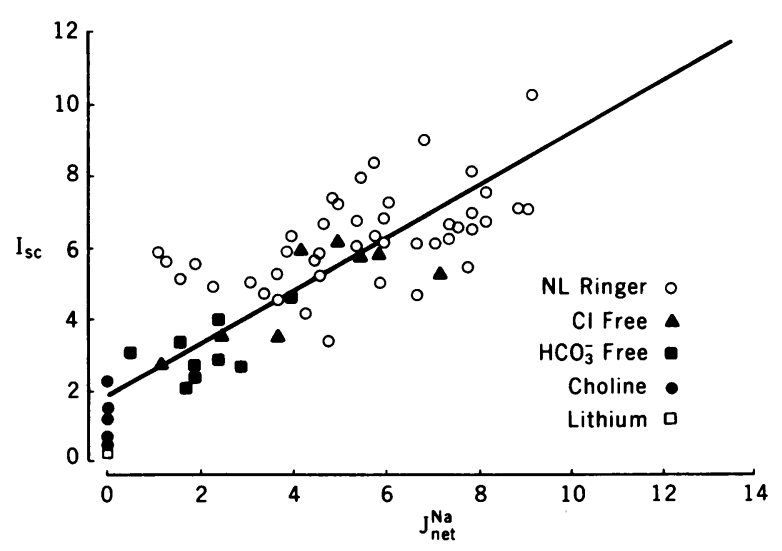

Figure 2. Correlation between $J_{\text {net }}$ and $I_{s c}$. There is a strong linear correlation $(r=0.8333)$ between rates of $\mathrm{Na}$ absorption and $I_{\mathrm{sc}}$ as $J_{\text {net }}^{\mathrm{Na}}$ increases from 0 to $10 \mu \mathrm{eq} \cdot \mathrm{cm}^{-2} \cdot \mathrm{h}^{-1}$ under a variety of conditions $(y=0.76 x+1.96)$. The data point for lithium represents four superimposed experiments. NL, normal. 
distal colon. The effect of amiloride $\left(10^{-4} \mathrm{M}\right)$ added to the mucosal reservoir was examined in rabbit cecum (Fig. 3). In both normal and $\mathrm{Cl}$-free Ringer's, amiloride did not alter $I_{\mathrm{sc}}$. After exposure to amiloride, both unidirectional fluxes of $\mathrm{Na}$ increased slightly $\left(J_{\mathrm{m}-\mathrm{s}}^{\mathrm{Na}}\right.$ from $7.6 \pm 0.5$ to $8.1 \pm 0.6$ $\mu$ eq $\cdot \mathrm{cm}^{-2} \cdot \mathrm{h}^{-1}, P=\mathrm{NS} ; J_{\mathrm{s}-\mathrm{m}}^{\mathrm{Na}}$ from $3.6 \pm 0.4$ to $4.8 \pm 0.7(P$ $=$ NS). $J_{\text {net }}^{\mathrm{Na}}$ decreased insignificantly because of the larger increase in $J_{s-\mathrm{m}}^{\mathrm{Na}}$. In Cl-free Ringer's, $J_{\text {net }}^{\mathrm{Na}}$ was unchanged after exposure to amiloride although both unidirectional fluxes increased. Additionally, $10^{-3} \mathrm{M}$ amiloride did not have a major effect on $I_{\text {sc }}$ (data not shown). Thus, in cecum, amiloride fails to block the absorptive flux of $\mathrm{Na}$ and does not alter $I_{\mathrm{sc}}$, implying a fundamentally different mechanism of $\mathrm{Na}$ absorption than that found in distal colon.

Phenamil inhibition of $I_{s c}$ and $J^{N a}$. The amiloride analogue phenamil inhibits electrogenic $\mathrm{Na}$ transport but at a substantially lower $K_{\mathrm{i}}$ than the parent compound in toad bladder (11). In contrast to amiloride, phenamil significantly decreased both $I_{\mathrm{sc}}$ and $J_{\mathrm{net}}^{\mathrm{Na}}$ in cecum. The dose-response curve (Fig. 4) indicates that $10^{-7}$ and $10^{-6} \mathrm{M}$ phenamil have no effect on electrical parameters; at $10^{-5} \mathrm{M}, I_{\mathrm{sc}}$ is inhibited by $19 \%$ and at $10^{-4}$ $M$, the current is blocked by $81 \%$. Neither pair-matched control tissues nor ceca exposed to amiloride exhibited changes in $I_{\mathrm{sc}}$. There is a corresponding reduction in conductance of 1.5 $\mathrm{mS} \cdot \mathrm{cm}^{-2}$ in immediate response to phenamil, suggesting concomitant inhibition of a conductive process. Compared with the amiloride response in distal colon, the phenamil-induced decrease in $I_{\mathrm{sc}}$ is relatively slow; the nadir of $I_{\mathrm{sc}}$ is reached in $\sim 15$ min. Additionally, we examined the effect of the loop diuretic furosemide, which blocks the coupled $\mathrm{Na}-\mathrm{Cl}$ (or $\mathrm{Na}-\mathrm{K}-2 \mathrm{Cl}$ ) cotransporter in a variety of epithelia. Furosemide did not have a significant effect on electrical parameters.

In well-defined systems of electrogenic transport, phenamil is $\sim 20$ times more potent than amiloride with a $K_{\mathrm{i}}$ in the range of $1.7 \times 10^{-8} \mathrm{M}$. In the cecum, phenamil's $K_{\mathrm{i}}$ for electrogenic Na transport is $\sim 5 \times 10^{-5} \mathrm{M}$. Thus, cecal Na transport is at least two orders of magnitude less sensitive to phenamil.

In toad bladder, phenamil irreversibly inhibits Na transport (11). In cecum, changing the bathing solution partially reverses the effect of phenamil (Fig. 4). 50\% of the phenamilinduced inhibition is irreversible, an effect similar to that seen in toad bladder. Thus, the failure of amiloride to block $\mathrm{Na}$
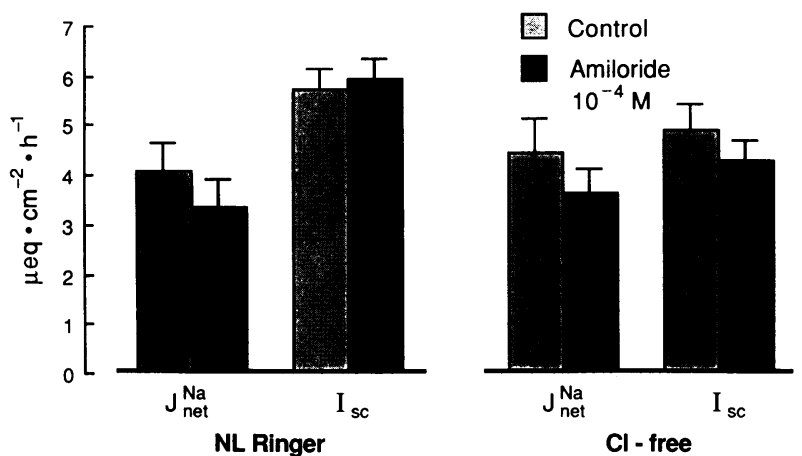

Figure 3. Amiloride effects on $J_{\text {net }}$ and $I_{\text {sc }}$. Amiloride $\left(10^{-4} \mathrm{M}\right)$ added to the mucosal solution failed to inhibit $J_{\text {net }}^{\mathrm{Na}}$ or $I_{\mathrm{sc}}$ in either normal (NL) Ringer's or Cl-free solutions. There are no statistically significant differences $(n=8)$.

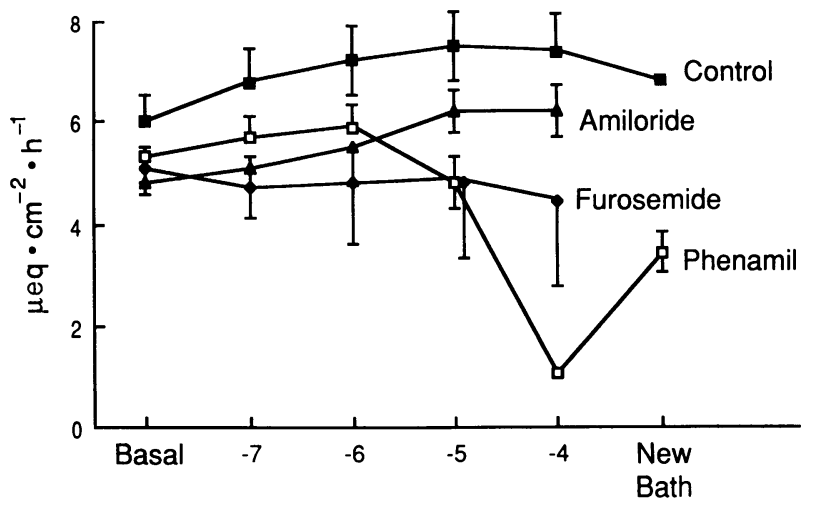

Figure 4. Dose-response curve for phenamil, amiloride, and furosemide. After tissue stabilization, the test drug was added in increasing concentration to the mucosal reservoir. Molar concentrations are plotted on the $x$-axis. In control and phenamil-treated tissues, the mucosal fluid was changed twice to test the reversibility of the drug's effect. There were 12 control, 8 phenamil, 5 amiloride, and 3 furosemide experiments.

transport and the high concentration of phenamil required to exert its effect both suggest that the amiloride-binding site for $\mathrm{Na}$ transport in the cecum has been substantially modified.

Amiloride has been shown to inhibit three distinct transport processes: electrogenic $\mathrm{Na}$ transport, $\mathrm{Na}-\mathrm{H}$ exchange, and $\mathrm{Na}-\mathrm{Ca}$ exchange. Amiloride analogues have been developed that differentially inhibit these three transport mechanisms. While phenamil has minimal effect on Na-H exchange $\left(K_{\mathrm{i}} \geqq 1\right.$ $\mathrm{mM}$ ), it has reasonable activity on inhibiting $\mathrm{Na}-\mathrm{Ca}$ exchange. To exclude the possibility that the observed effect of phenamil was via $\mathrm{Na}-\mathrm{Ca}$ exchange, we tested three amiloride analogues that are primarily $\mathrm{Na}-\mathrm{Ca}$ exchange inhibitors. The three agents (5- $N$-propyl- $N$-butyl)-2'4'-dichlorobenzamil， 5-[N[(4-chloro benzyl)-2'4' dimethyl benzamil, and 2'4'-dimethyl benzamil) all failed to alter electrical parameters in the cecum (data not shown).

Flux studies were performed to confirm that the change in $I_{\mathrm{sc}}$ was due to a change in $J_{\mathrm{net}}^{\mathrm{Na}}$. In both the normal and chloride-free Ringer's, there was a strong correlation between the change in current and net $\mathrm{Na}$ flux (Table III). Both $I_{\mathrm{sc}}$ and $J_{\text {net }}^{\mathrm{Na}}$ were reduced by $4.5-5.0 \mu \mathrm{eq} \cdot \mathrm{cm}^{-2} \cdot \mathrm{h}^{-1}$. In normal Ringer's, the decrease in $J_{\text {net }}^{\mathrm{Na}}$ was due primarily to a decrease in $J_{\mathrm{m}-\mathrm{s}}^{\mathrm{Na}}$, consistent with inhibition of conductive $\mathrm{Na}$ entry. In chloridefree Ringer, the change in $J_{\text {net }}^{\mathrm{Na}}$ was due primarily to a change in $J_{s-m}^{\mathrm{Na}}$. This pattern is similar to that seen in the series of experiments with amiloride in Cl-free Ringer. Under those conditions, $J_{s-\mathrm{m}}^{\mathrm{Na}}$ increased from $2.2 \pm 0.2$ to $3.4 \pm 0.6 \mu \mathrm{eq} \cdot \mathrm{cm}^{-2} \cdot \mathrm{h}^{-1}$ $(P=0.005)$ with a corresponding increase in $J_{\mathrm{m}-\mathrm{s}}^{\mathrm{Na}}$; there were, however, no significant changes in $J_{\mathrm{net}}^{\mathrm{Na}}$ or $I_{\mathrm{sc}}$. Thus, the increase in $J_{s-m}^{\mathrm{Na}}$ in Cl-free Ringer's is most likely due to associated conductance changes and independent of changes in $I_{\mathrm{sc}}$. In this context, the trend towards decreased $J_{\mathrm{m}-\mathrm{s}}^{\mathrm{Na}}$ in response to phenamil may be interpreted as not inconsistent with the findings of phenamil's effect in normal Ringer's.

$10^{-4} \mathrm{M}$ phenamil does not block $I_{\mathrm{sc}}$ entirely, while it decreased $J_{\text {net }}^{\mathrm{Na}}$ to zero. This, along with the observation that there is a significant $I_{\mathrm{sc}}$ in choline Ringer's, suggests that there are additional electrogenic processes in cecum. The possible sources for this current are $\mathrm{K}$ absorption or $\mathrm{HCO}_{3}$ secretion (see below). 
Table III. Phenamil Inhibition of $I_{s c}$ and $J_{\text {net }}{ }^{\text {Na }}$

\begin{tabular}{|c|c|c|c|c|c|}
\hline Group & \multicolumn{3}{|c|}{$J^{\mathrm{Na}}$} & $I_{x c}$ & $G_{\mathrm{t}}$ \\
\hline & \multicolumn{4}{|c|}{$\mu e q \cdot \mathrm{cm}^{-2} \cdot \mathrm{h}^{-1}$} & $\mathrm{mS} \cdot \mathrm{cm}^{-2}$ \\
\hline \multicolumn{6}{|l|}{ A. Normal Ringer's } \\
\hline Control & $8.3 \pm 0.7$ & $4.6 \pm 0.5$ & $3.6 \pm 0.9$ & $6.64 \pm 0.50$ & $6.6 \pm 0.8$ \\
\hline Phenamil $10^{-4} \mathrm{M}$ & $5.6 \pm 0.3$ & $6.6 \pm 0.8$ & $-0.9 \pm 0.6$ & $1.71 \pm 0.40$ & $6.6 \pm 0.7$ \\
\hline \multicolumn{6}{|l|}{ B. Chloride-free } \\
\hline Control & $7.8 \pm 1.3$ & $3.9 \pm 0.7$ & $3.9 \pm 1.6$ & $5.49 \pm 1.10$ & $4.4 \pm 0.5$ \\
\hline Phenamil $10^{-4} \mathrm{M}$ & $6.7 \pm 0.5$ & $7.9 \pm 0.8$ & $-1.0 \pm 0.6$ & $0.94 \pm 0.24$ & $5.4 \pm 0.9$ \\
\hline$P$ & NS & .003 & .02 & .007 & NS \\
\hline
\end{tabular}

Group A results are given for four animals. Phenamil was added to the mucosal chamber after the initial control flux. In a different series of rabbit ceca bathed with chloride-free Ringer's (group B), phenamil $10^{-4} \mathrm{M}$ blocked $J_{\text {net }}{ }^{\mathrm{Na}}(n=5$ ).

Modifying effects of sulfhydryl reagents. Pharmacologic agents that modify membrane sulfhydryl groups have previously been shown to alter the transport characteristics of amiloride-sensitive electrogenic $\mathrm{Na}$ transport in a variety of tight epithelia. Mercurial compounds such as PCMBS presumably form mercaptide bonds with exposed -SH groups in apical membranes (12). We therefore examined the effect of $10^{-3}$ PCMBS on the electrical parameters of cecal $\mathrm{Na}$ transport (Fig. 5).

PCMBS initiated a gradual increase in $I_{\mathrm{sc}}$ and $G_{\mathrm{t}}$, reaching a plateau at $\sim 15 \mathrm{~min}$. Addition of phenamil caused a decrease of $I_{\mathrm{sc}}$ of $14.7 \mu \mathrm{eq} \cdot \mathrm{cm}^{-2} \cdot \mathrm{h}^{-1}$, from 17.5 to 2.8 $\mu \mathrm{eq} \cdot \mathrm{cm}^{-2} \cdot \mathrm{h}^{-1}$. This was accompanied by a decrease in conductance of $3 \mathrm{mS} \cdot \mathrm{cm}^{-2}$. However, PCMBS added after phenamil had no significant effect on either $I_{\mathrm{sc}}$ or $G_{\mathrm{t}}$. There was no difference in the post-phenamil electrical parameters, regardless of whether the tissue had been exposed to PCMBS or not. Thus, PCMBS significantly stimulates a phenamil-inhibitible increase in $I_{\text {sc }}$; pretreatment of the cecal epithelium with phenamil blocks the effect of PCMBS.

Potassium fluxes in rabbit cecum (Table IV). Steady-state fluxes in the cecum indicate that, under basal conditions, potassium is secreted. Addition of phenamil does not significantly alter $\mathrm{K}$ transport. Thus, potassium absorption is un-

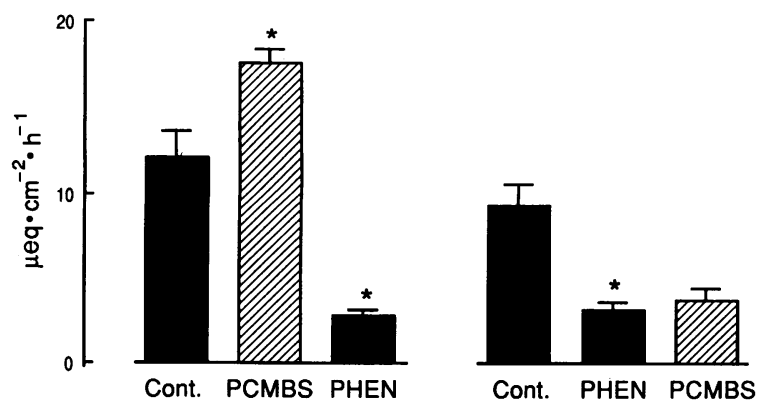

Figure 5. Effects of PCMBS and phenamil (PHEN) on $I_{\mathrm{sc}}$. PCMBS $\left(10^{-3} \mathrm{M}\right)$ caused a significant increase in $I_{\mathrm{sc}}$. Phenamil $\left(10^{-4} \mathrm{M}\right) \mathrm{re}-$ versed this effect and inhibited most of the basal $I_{\mathrm{sc}}$. PCMBS added after phenamil did not increase $I_{\mathrm{sc}} .{ }^{*} P 0.05, n=7$ for each group. likely to be the source of the residual current either after addition of phenamil or in choline-free Ringer's.

Epinephrine stimulates $\mathrm{Na}$ absorption. Epinephrine, as an $\alpha 2$ adrenergic agonist, stimulates electrically neutral $\mathrm{Na}-\mathrm{Cl}$ co transport $(13,14)$. In cecum, epinephrine $5.5 \times 10^{-6} \mathrm{M}$ added serosally stimulates electroneutral $\mathrm{Na}$ absorption (Table $\mathrm{V}$ ). This occurs primarily through an increase in $J_{\mathrm{m}-\mathrm{s}}^{\mathrm{Na}}$. The increase in $J_{\text {net }}^{\mathrm{C}}$ is not significant; $J_{\mathrm{m}-\mathrm{s}}^{\mathrm{Cl}}$ does not change, but $J_{\mathrm{s}-\mathrm{m}}^{\mathrm{Cl}}$ decreases from $7.6 \pm 0.8$ to $6.4 \pm 0.7 \mu \mathrm{eq} \cdot \mathrm{cm}^{-2} \cdot \mathrm{h}^{-1}, P=0.0507$. Given the increased conductance and the trend over time for fluxes to increase, this probably represents a decrease in transcellular $J_{s-\mathrm{m}}^{\mathrm{Cl}}$. In bicarbonate-free Hepes-buffered solutions, epinephrine does not stimulate net $\mathrm{Na}$ absorption (control $2.1 \pm 0.3$, post-epinephrine $2.0 \pm 0.7 \mu \mathrm{eq} \cdot \mathrm{cm}^{-2} \cdot \mathrm{h}^{-1}, n=8, P$ NS). Thus, there is a component of $\mathrm{Na}$ transport that is electroneutral, bicarbonate dependent, and epinephrine sensitive. It is not clearly coupled to $\mathrm{Cl}$ movement and is of lesser magnitude than that found in the proximal colon (1).

Response to secretagogues. The secretory response of cecum was assessed by examining the effect of 8BrcAMP, 8BrcGMP, and theophylline (Table VI). The three secretagogues elicited a similar pattern of response. $I_{\mathrm{sc}}$ rose by 1.5 $\mu \mathrm{eq} \cdot \mathrm{cm}^{-2} \cdot \mathrm{h}^{-1}$ after addition of 8BrcAMP, 8BrcGMP, and theophylline. There were no significant alterations in either unidirectional or net $\mathrm{Na}$ fluxes. However, $\mathrm{Cl}$ fluxes changed in a manner consistent with electrogenic $\mathrm{Cl}$ secretion: under all three conditions $J_{\mathrm{s}-\mathrm{m}}^{\mathrm{Cl}}$ increased. $J_{\mathrm{m}-\mathrm{s}}^{\mathrm{Cl}}$ either stayed the same (cGMP, theophylline) or increased modestly (cAMP); $J_{\text {net }}^{\mathrm{Cl}}$ decreased. The changes in $\mathrm{Cl}$ transport was of the same order of magnitude as the change in $I_{\mathrm{sc}}$. Therefore, the cecum exhibits a modest capacity for electrogenic $\mathrm{Cl}$ secretion; secretory stimuli do not alter $\mathrm{Na}$ transport.

Bicarbonate transport. By employing a pH stat system, we measured the rates of luminal and serosal alkalinization (Fig. 6). This experimental design requires one side of the tissue to be bathed in $\mathrm{HCO}_{3}$ Ringer's with the opposite side exposed to a $\mathrm{HCO}_{3}$-free solution. Under these conditions, it is readily apparent that $I_{\mathrm{sc}}$ was significantly higher in the absence of mucosal $\mathrm{HCO}_{3}\left(5.19 \pm 0.58 \mu \mathrm{eq} \cdot \mathrm{cm}^{-2} \cdot \mathrm{h}^{-1}\right)$ than serosal $\mathrm{HCO}_{3}$ $\left(3.01 \pm 0.25 \mu \mathrm{eq} \cdot \mathrm{cm}^{-2}\right.$ ) $P=0.003$ (Fig. 4). This suggests that the changes seen in $I_{\mathrm{sc}}$ and $J_{\text {net }}^{\mathrm{Na}}$ in $\mathrm{HCO}_{3}$-free solutions (Table I) 


\begin{tabular}{|c|c|c|c|c|c|}
\hline & \multicolumn{3}{|c|}{$J^{\mathbf{K}}$} & \multirow[b]{2}{*}{$I_{\mathrm{xc}}$} & \multirow[b]{2}{*}{$G_{\mathrm{t}}$} \\
\hline & m-s & s-m & net & & \\
\hline & \multicolumn{4}{|c|}{$\mu e q \cdot \mathrm{cm}^{-2} \cdot \mathrm{h}^{-1}$} & $\mathrm{mS} \cdot \mathrm{cm}^{-2}$ \\
\hline Control (5) & $0.20 \pm 0.05$ & $0.73 \pm 0.10$ & $-0.52 \pm 0.09$ & $7.65 \pm 0.74$ & $6.2 \pm 0.7$ \\
\hline Phenamil (4) & $0.15 \pm 0.04$ & $0.65 \pm 0.06$ & $-0.40 \pm 0.13$ & $1.44 \pm 0.14^{*}$ & $6.5 \pm 0.5$ \\
\hline
\end{tabular}

Number of animals is given in parentheses. An initial flux period measured basal $\mathrm{K}$ fluxes in cecum. A subsequent flux period assessed the changes in $\mathrm{K}$ transport after the addition of phenamil. Resistance matches were lost in one experiment during the second period flux. ${ }^{*} P$ $<0.05$ vs. control.

are due to the absence of serosal $\mathrm{HCO}_{3}$ and are not related to inhibition of a coupled $\mathrm{Na}-\mathrm{HCO}_{3}$ entry across the apical membrane. Although $J_{\mathrm{m}-\mathrm{s}}^{\mathrm{HCO}_{3}}$ and $J_{\mathrm{s}-\mathrm{m}}^{\mathrm{HCO}_{3}}$ were roughly equivalent, suggesting that, under basal conditions, a minimal amount of transcellular $\mathrm{HCO}_{3}$ transport occurs, calculation of net $\mathrm{HCO}_{3}$ transport from these data is not warranted because the flux measurements were obtained with imposed chemical gradients that differentially altered the electrical parameters and ion transport characteristics of the epithelium.

In response to epinephrine, $J_{\mathrm{m}-\mathrm{s}}^{\mathrm{HCO}_{3}}$ increases from $1.8 \pm 0.7$ to $3.2 \pm 0.7 \mu \mathrm{eq} \cdot \mathrm{cm}^{-2} \cdot \mathrm{h}^{-1}(P=0.022)$ while $J_{s-\mathrm{m}}^{\mathrm{HCO}_{3}}$ remains essentially unchanged $\left(1.3 \pm 0.6\right.$ before; $1.4 \pm 0.5 \mu \mathrm{eq} \cdot \mathrm{cm}^{-2} \cdot \mathrm{h}^{-1}$ post-epinephrine $(P$ NS). This suggests that epinephrine elicits active $\mathrm{HCO}_{3}$ absorption in rabbit cecum in addition to its effects on $\mathrm{Na}$ transport.

\section{Discussion}

Recent studies have clearly established that there is a signifcant segmental heterogeneity of ion transport properties in the colon. Whereas $\mathrm{Na}$ absorption in the distal colon is electrogenic and inhibited by low-dose amiloride, $\mathrm{Na}$ transport in proximal colon is electroneutral and unaffected by low-dose amiloride (1). It is becoming increasingly apparent that there are variations within the rabbit proximal colon; the $3 \mathrm{~F}$ (triplehaustrated) segment within $10 \mathrm{~cm}$ of the proximal colon exhibits different transport parameters from the $1 \mathrm{~F}$ (single-haustrated) segment of more distal (beyond $10 \mathrm{~cm}$ ) proximal colon. Our observations indicate that the cecum is significantly different from the proximal colon and possesses a distinct mechanism for $\mathrm{Na}$ absorption.

Basal electrical measurements reveal that the rabbit cecum exhibits a strikingly higher basal $I_{\mathrm{sc}}$ in comparison with other intestinal segments. The $I_{\mathrm{sc}}$ of $6 \mu \mathrm{eq} \cdot \mathrm{cm}^{-2} \cdot \mathrm{h}^{-1}$ is roughly dou- ble that found in ileum or distal colon; in fact, it is in the range found in glucose-stimulated ileum or steroid-treated distal colon $(9,15)$. Although studies examining cecal ion transport are limited, both Clauss et al. (4) (in the rabbit) and Will et al. (16) (in the rat) have found the highest $I_{\mathrm{sc}}$ within the intestine in the cecum. However Loeschke et al. (17), studying the effects of small bowel resection found cecal PD lower than that of colon.

Cecum absorbs Na efficiently. Several lines of evidence suggest that this $\mathrm{Na}$ absorption is electrogenic. There is a strong correlation between $J_{\text {net }}^{\mathrm{Na}}$ and $I_{\text {sc }}$ (Fig. 2). As [Na] in the bathing media increases, there is a proportionate rise in $I_{\mathbf{s c}}$. The increase is linear and begins to saturate at $100 \mathrm{mM}[\mathrm{Na}]_{0}$. Maneuvers that cause a change in $J_{\text {net }}^{\mathrm{Na}}$ are accompanied by equivalent changes in $I_{\mathrm{sc}}$. For example, $\mathrm{Na}$ replacement decreases both $I_{\mathrm{sc}}$ and $J_{\mathrm{net}}^{\mathrm{Na}}$ proportionately. Anion replacement causes similar changes in both $J_{\text {net }}^{\mathrm{Na}}$ and $I_{\mathrm{sc}}$. Most importantly, phenamil has an equivalent effect on $I_{\mathrm{sc}}$ and $J_{\mathrm{net}}^{\mathrm{Na}}$. The equivalence of $J_{\mathrm{net}}^{\mathrm{Na}}$ and $I_{\mathrm{sc}}$ under a wide variety of conditions suggests that $\mathrm{Na}$ absorption is electrogenic.

However, the mechanism of cecal Na transport is not typical of "classic" epithelial electrogenic $\mathrm{Na}$ absorption, such as found in distal colon. Inhibition of $\mathrm{Na}$ absorption by low-dose $\left(10^{-4}\right.$ or $\left.10^{-5} \mathrm{M}\right)$ amiloride has almost become an operative definition of electrogenic $\mathrm{Na}$ transport. In our studies, amiloride failed to block either $\mathrm{Na}$ absorption or $I_{\mathrm{sc}}$. In distal colon, an equivalent dose of amiloride abolishes both $J_{\text {net }}^{\mathrm{Na}}$ and $I_{\mathrm{sc}}$. Interestingly, Clauss et al. (4) have also observed a lack of effect of amiloride in rabbit cecum while Will et al. (16) were able to demonstrate only a $3 \%$ inhibition of $I_{s c}$ by amiloride. Thus, unlike distal colon, electrogenic $\mathrm{Na}$ transport in cecum appears to be resistant to amiloride.

There are several additional factors that differentiate $\mathrm{Na}$ transport in the rabbit cecum from that in distal colon. $I_{\mathbf{s c}}$ and

Table V. Effects of Epinephrine in Cecum

\begin{tabular}{|c|c|c|c|c|c|c|c|c|c|}
\hline & \multicolumn{3}{|c|}{$J^{N_{2}}$} & \multicolumn{3}{|c|}{$\mathrm{ja}^{\mathrm{a}}$} & \multirow[b]{2}{*}{$I_{\boldsymbol{x}}$} & \multirow[b]{2}{*}{$j^{\mathbf{R}}$} & \multirow[b]{2}{*}{$G_{\mathrm{t}}$} \\
\hline & m-s & s-m & net & m-s & s-m & net & & & \\
\hline & \multicolumn{8}{|c|}{$\mu e q \cdot \mathrm{cm}^{-2} \cdot h^{-1}$} & $\mathrm{mS} \cdot \mathrm{cm}^{-2}$ \\
\hline I Control & $9.7 \pm 1.6$ & $3.8 \pm 0.7$ & $5.9 \pm 1.3$ & $8.3 \pm 0.6$ & $7.6 \pm 0.8$ & $0.9 \pm 1.2$ & $6.44 \pm 0.43$ & $1.5 \pm 0.6$ & $7.1 \pm 0.8$ \\
\hline II Epinephrine & $12.9 \pm 1.3$ & $5.1 \pm 0.8$ & $7.8 \pm 1.1$ & $8.4 \pm 0.5$ & $6.4 \pm 0.7$ & $2.0 \pm 0.8$ & $6.98 \pm 0.46$ & $1.2 \pm 0.5$ & $12.0 \pm 1.2$ \\
\hline$P$ & 0.0001 & 0.043 & 0.019 & NS & 0.051 & NS & NS & NS & 0.001 \\
\hline
\end{tabular}

Results are given for 10 animals. The protocol for these studies involved an initial basal flux period of 30 min (I control), addition of $5.5 \times 10^{-6} \mathrm{M}$ epinephrine to the serosal reservoir during a 20 -min stabilization period and a subsequent 40 -min flux (II Epinephrine). 


\begin{tabular}{|c|c|c|c|c|c|c|c|c|c|}
\hline & \multicolumn{3}{|c|}{$J^{\mathrm{Na}}$} & \multicolumn{3}{|c|}{$J^{a}$} & \multirow[b]{2}{*}{$I_{\boldsymbol{x}}$} & \multirow[b]{2}{*}{$J^{R}$} & \multirow[b]{2}{*}{$G_{\mathrm{t}}$} \\
\hline & m-s & s-m & net & m-s & s-m & net & & & \\
\hline & \multicolumn{8}{|c|}{$\mu e q \cdot \mathrm{cm}^{-2} \cdot \mathrm{h}^{-1}$} & $\mathrm{mS} \cdot \mathrm{cm}^{-2}$ \\
\hline \multicolumn{10}{|l|}{ I. Theophylline } \\
\hline Control & $10.2 \pm 0.6$ & $4.8 \pm 0.6$ & $5.4 \pm 0.6$ & $10.7 \pm 0.3$ & $8.4 \pm 0.5$ & $2.3 \pm 0.7$ & $6.47 \pm 0.33$ & $3.4 \pm 0.6$ & $7.8 \pm 0.6$ \\
\hline $\begin{array}{l}\text { Theophylline } \\
\text { (5) }\end{array}$ & $10.9 \pm 0.8$ & $5.0 \pm 0.7$ & $5.9 \pm 0.7$ & $9.8 \pm 0.6$ & $9.9 \pm 0.8$ & $-0.1 \pm 0.6$ & $8.13 \pm 0.44$ & $2.2 \pm 0.6$ & $11.3 \pm 1.15$ \\
\hline$P$ & NS & NS & NS & NS & 0.0397 & NS & 0.0011 & NS & NS \\
\hline \multicolumn{10}{|l|}{ II. 8 BrcAMP } \\
\hline Control & $9.0 \pm 0.7$ & $3.8 \pm 0.7$ & $5.2 \pm 0.4$ & $8.0 \pm 0.7$ & $6.0 \pm 0.9$ & $2.0 \pm 0.5$ & $6.10 \pm 0.3$ & $2.9 \pm 0.6$ & $6.5 \pm 0.4$ \\
\hline $\begin{array}{c}\text { cAMP } \\
(8)\end{array}$ & $9.8 \pm 1.3$ & $4.3 \pm 0.7$ & $5.5 \pm 0.9$ & $9.8 \pm 1.3$ & $8.9 \pm 1.1$ & $0.9 \pm 0.6$ & $7.41 \pm 0.5$ & $2.8 \pm 0.6$ & $9.6 \pm 1.7$ \\
\hline$P$ & NS & NS & NS & 0.0496 & 0.0055 & 0.0085 & 0.0047 & NS & NS \\
\hline \multicolumn{10}{|l|}{ III. 8BrcGMP } \\
\hline Control & $10.3 \pm 0.6$ & $2.5 \pm 0.4$ & $7.8 \pm 0.4$ & $10.7 \pm 0.9$ & $7.8 \pm 1.0$ & $2.9 \pm 1.0$ & $6.57 \pm 0.20$ & $1.6 \pm 1.1$ & $6.3 \pm 0.3$ \\
\hline $\begin{array}{c}\text { cGMP } \\
(8)\end{array}$ & $11.8 \pm 1.2$ & $3.7 \pm 0.6$ & $8.1 \pm 1.2$ & $10.1 \pm 1.0$ & $8.7 \pm 0.7$ & $1.4 \pm 1.0$ & $8.50 \pm 0.50$ & $1.9 \pm 0.7$ & $8.7 \pm 1.1$ \\
\hline$P$ & NS & NS & NS & NS & NS & 0.0279 & 0.0022 & NS & 0.0327 \\
\hline
\end{tabular}

The number of animals for each group is given in parentheses. The protocol for these experiments consisted of a control flux, addition of secretagogue to the serosal reservoir $\left(10^{-3} \mathrm{M}\right.$ theophylline, $\left.10^{-4} \mathrm{BrcAMP}, 10^{-4} 8 \mathrm{BrcGMP}\right)$, and a second flux period.

$J_{\text {net }}^{\mathrm{Na}}$ are clearly related to external $\mathrm{Na}\left([\mathrm{Na}]_{\mathrm{o}}\right)$ in both distal colon and cecum; however, in distal colon $I_{\mathrm{sc}}$ and $J_{\mathrm{net}}^{\mathrm{Na}}$ appear to "saturate" at a much lower $[\mathrm{Na}]_{\mathrm{o}}(40-60 \mathrm{mM})$ than in cecum, suggesting that, on a macroscopic basis at least, the kinetics of transport are different.

The response to anion substitution also differentiates cecum and distal colon. In distal colon, $\mathrm{Cl}$ replacement with a series of impermeant anions results in a rise in $I_{\mathrm{sc}}$ and enhancement of $J_{\text {net }}^{\mathrm{Na}}(18)$. In cecum, chloride replacement with sulfate causes a modest decrease in both $I_{\mathrm{sc}}$ and $J_{\text {net }}^{\mathrm{Na}}$. While $\mathrm{HCO}_{3}$ has previously been shown to stimulate neutral $\mathrm{Na}$ absorption in the gallbladder (19), it has not, to our knowledge, been demon-
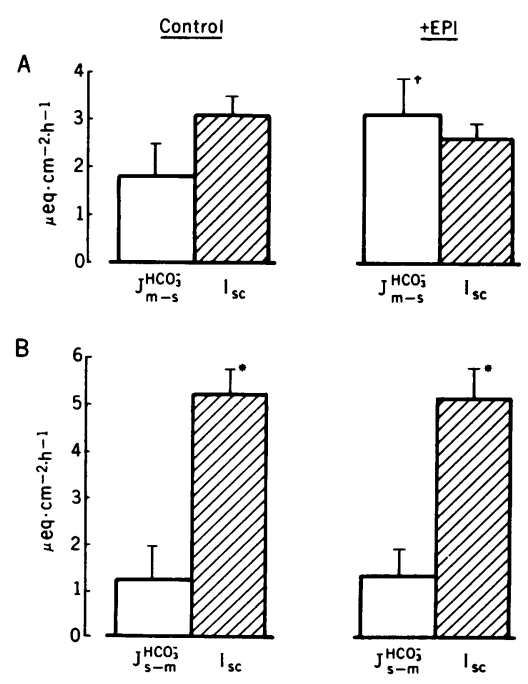

Figure 6. Bicarbonate transport in cecum. $(A)$ $J_{\mathrm{m}-\mathrm{s}}^{\mathrm{HCO}_{3}}$ increases significantly after exposure to $5.5 \mu \mathrm{M}$ epinephrine without a change in $I_{\mathrm{sc}}$. (B) $J_{\mathrm{s}-\mathrm{m}}^{\mathrm{HCO}}$ is unchanged by an identical dose of epinephrine. The $I_{\mathrm{sc}}$ in ceca exposed to a bicarbonate-free serosal solution $(A)$ exhibit a significantly lower $I_{\mathrm{sc}}$ than pair-matched tissues in which serosal $\mathrm{HCO}_{3}$ was present $(B)$. See text for details of experimental protocol. $\nmid P$ 0.05 vs. control $J_{\mathrm{m}-\mathrm{s}}^{\mathrm{HCO}_{3}}$. ${ }^{*} P 0.005$ vs. corresponding $I_{\mathrm{sc}}$ in A. strated to have a significant effect on electrogenic Na transport.

Phenamil inhibits electrogenic Na transport. Phenamil clearly inhibits both $I_{\mathrm{sc}}$ and $J_{\mathrm{net}}^{\mathrm{Na}}$. This observation provides an important insight into the mechanisms of electrogenic $\mathrm{Na}$ absorption in the cecum. The present data are most consistent with significant alterations of the binding sites associated with the classical $\mathrm{Na}$ channel rather than a fundamentally distinct channel. Work by several investigators studying electrogenic $\mathrm{Na}$ absorption in a variety of tight epithelia has suggested that there are specific loci associated with the $\mathrm{Na}$ channel that modify its behavior: an amiloride-binding site (20), a $\mathrm{Na}$ self-inhibition site $(21,22)$, a sulfhydryl group sensitive to mercurial agents (12), a trypsin-sensitive site (23), and a methyl receptor locus (24). There may be overlap among these sites; however, it appears that the amiloride-binding and $\mathrm{Na}$ self-inhibition sites are distinct (20).

Although amiloride has no effect on electrogenic Na absorption in cecum, phenamil does inhibit both $I_{\mathrm{sc}}$ and $J_{\mathrm{net}}^{\mathrm{Na}}$. Compared with its effect in other epithelia, phenamil in cecum acts only in high doses. These observations suggest that the interaction between the amiloride analogues and a specific binding site associated with the channel are much weaker in cecum than in other epithelia.

Lindemann has described the phenomenon of Na self-inhibition, in which increasing [ $\mathrm{Na}$ ] bathing the apical membrane of tight epithelia results in closure of $\mathrm{Na}$ channels $(21,22)$. Presumably $\mathrm{Na}^{+}$ions react with specific modifying sites located in the vicinity of the Na-conductive channel; the channel closes when the site is occupied by Na. This leads to the typical type of saturation kinetics associated with $\mathrm{Na}$ absorption in the distal colon. In cecum, however, there is no obvious "saturation"; the rise in $I_{\mathrm{sc}}$ parallels the increase in [Na] to $100 \mathrm{mM}$. 
This is consistent with a lack of self-inhibition, which may be due to an absent or ineffective self-inhibition site.

Sulfhydryl reagents alter electrogenic $\mathrm{Na}$ transport in a variety of epithelia. In rabbit distal colon, PCMBS "freezes" the $\mathrm{Na}$ conductance of the apical membrane at a mean value of 2-3 $\mu \mathrm{eq} \cdot \mathrm{cm}^{-2} \cdot \mathrm{h}^{-1}$ and renders the transport amiloride-insensitive (25). Sulfhydryl reagents also stimulate electrogenic $\mathrm{Na}$ absorption in frog skin $(12,26)$; however, in contrast to distal colon, this $\mathrm{Na}$ transport is blocked by amiloride. The response of the cecum to PCMBS and phenamil is similar to that found in frog skin rather than distal colon: i.e., sulfhydryl reagent stimulation of $\mathrm{Na}$ transport that retains its sensitivity to an amiloride analogue. Thus, the $\mathrm{Na}$ transport system in rabbit cecum is associated with sulfhydryl groups that can be modified by mercurial agents.

Although there is considerable evidence for in vitro pharmacologic modification of $\mathrm{Na}$ channels, there is also some precedent for in vivo alterations of this transport system (27, 28). Along these lines, Leng-Peschlow and Marty (29) have observed that, in a surgically created cecal pouch, pretreatment of the pouch with cecal contents over several days resulted in net absorption of $\mathrm{Na}$ and water. In contrast, pouches exposed only to electrolyte solutions secreted $\mathrm{Na}$ and water. Considering the degree of stasis normally found in the rabbit cecum, it is conceivable that there may be a bacterial enzymatic effect on the epithelium. Our in vitro data are consistent with an electrogenic $\mathrm{Na}$ transport system (i.e., channel) in which the modifying effects of $\mathrm{Na}$ self-inhibition and amiloride binding have been altered.

Effect of epinephrine. There is little evidence for electroneutral $\mathrm{Na}$ absorption under basal conditions in cecum. However, epinephrine stimulates $\mathrm{Na}$ absorption (from $5.9 \pm 1.3$ to $7.8 \pm 1.1 \mu \mathrm{eq} \cdot \mathrm{cm}^{-2} \cdot \mathrm{h}^{-1}$ with little change in $I_{\mathrm{sc}}$. Although $J_{\mathrm{s}-\mathrm{m}}^{\mathrm{Cl}}$ decreases significantly, there is no increase in the absorptive flux of $\mathrm{Cl}$. However, as the $\mathrm{pH}$ stat data indicates, epinephrine elicits an increase in $J_{\mathrm{m}-\mathrm{s}}^{\mathrm{HCO}_{3}}$ from $1.8 \pm 0.7$ to $3.2 \pm 0.7$ $\mu \mathrm{eq} \cdot \mathrm{cm}^{-2} \cdot \mathrm{h}^{-1}$ without a change in $J_{\mathrm{s}-\mathrm{m}}^{\mathrm{HCO}}$. Thus epinephrinestimulated $\mathrm{Na}$ transport in the cecum is accompanied by changes in $\mathrm{HCO}_{3}$ fluxes. Similar results have been reported by Smith and Sullivan $(5,30)$ in both ileum and the proximal portion of the proximal colon. We also observed that epinephrine-stimulated $\mathrm{Na}$ absorption did not occur in $\mathrm{HCO}_{3}$-free solutions. Electroneutral $\mathrm{Na}$ transport in the cecum, therefore, appears to be linked to $\mathrm{HCO}_{3}$. Compared with the amount of electrogenic $\mathrm{Na}$ transport, electroneutral $\mathrm{Na}$ absorption is a relatively minor component of overall $\mathrm{Na}$ absorption in the cecum.

Anion transport, electrogenic secretion, and residual current. A modest rate of basal $\mathrm{Cl}$ absorption was present in the cecum. Na substitution with choline did not significantly alter $\mathrm{Cl}$ absorption; ceca bathed in $\mathrm{HCO}_{3}$-free fluid exhibited a modest reversal to $\mathrm{Cl}$ secretion. With an imposed transepithelial $\mathrm{HCO}_{3}$ gradient during the $\mathrm{pH}$ stat experiments, the cecum demonstrated bidirectional $\mathrm{HCO}_{3}$ transport. ${ }^{2}$

\footnotetext{
2. Because of the necessary constraints of pH stat measurements, transepithelial chemical equilibrium cannot be achieved. Therefore, it is not possible to measure a true net transport for bicarbonate as can be done for $\mathrm{Na}$ and $\mathrm{Cl}$. However, given the imposed gradients, $J_{\mathrm{m}-\mathrm{s}}^{\mathrm{HCO}_{3}}$ and $J_{\mathrm{s}-\mathrm{m}}^{\mathrm{HCO}}$ are roughly equivalent in pair-matched tissues from the same animal, suggesting that there is no major active component of basal bicarbonate transport.
}

Both cAMP- and cGMP-mediated secretagogues elicited a response consistent with electrogenic $\mathrm{Cl}$ secretion. The change in $I_{\mathrm{sc}}$ we demonstrated is similar to that found by Rao et al. (31). (No flux measurements were performed in that latter study.) The flux studies do not indicate inhibition of neutral $\mathrm{Na}-\mathrm{Cl}$ cotransport. The rabbit cecum, then, is analogous to the proximal colon: under basal conditions, electroneutral $\mathrm{Na}$ absorption is nil; secretagogues do not alter basal $\mathrm{Na}$ absorption; but epinephrine can elicit electroneutral $\mathrm{Na}$ absorption. However, unlike proximal colon, the cecum has the capacity for electrogenic $\mathrm{Cl}$ secretion.

Although $\mathrm{Na}$ absorption in the cecum is electrogenic, there is substantial evidence that there are additional electrogenic transport processes operative in this epithelium. In Na-free choline Ringer's, a significant current remains. In normal Ringer's, phenamil blocks $\mathrm{Na}$ absorption but does not eliminate $I_{\mathrm{sc}}$ entirely. Flux studies indicate that neither chloride nor potassium fluxes can account for the residual current. The situation with $\mathrm{HCO}_{3}$ is complex since "net fluxes" can not be calculated (see above). However, it is possible, given the postphenamil current in $\mathrm{Cl}$-free Ringer's, that there is a component of $\mathrm{HCO}_{3}$ secretion.

The cecum in context. It has become increasingly apparent that the gut, much like the nephron, has elaborate segmental variations. The rabbit cecum is voluminous; it comprises $50 \%$ of the macrosurface area of the colon and therefore is likely to have a major effect on colonic ion transport. Additionally, because of cecal stasis, the contact time of the luminal fluid with the epithelium is prolonged in comparison with the remainder of the gut, potentiating its role in intestinal fluid balance.

Prior in vivo studies have suggested that the bulk of colonic fluid is absorbed proximally rather than distally. However, we had previously shown that basal electrolyte absorption in the rabbit proximal colon is insignificant (1). The finding that the cecum has a major absorptive capacity for $\mathrm{Na}$ may help, in part, to resolve these discrepancies. Additionally, although the cecum does respond to secretagogues with electrogenic $\mathrm{Cl}$ secretion, $\mathrm{Na}$ absorption is unaltered and the total osmolar flux remains absorptive. Thus, in the face of secretory stimuli, the cecum may retain the ability to conserve fluid.

The major transport pathway in the cecum is electrogenic $\mathrm{Na}$ absorption that is amiloride insensitive, but blocked by phenamil. There is some precedent for such an absorptive mechanism. In ileum there appears to be a component of $\mathrm{Na}$ absorption that is electrogenic and not coupled to nutrient absorption (32). Additionally, recent studies in human colon in vitro have suggested that there is chloride-independent, amiloride-insensitive electrogenic $\mathrm{Na}$ absorption (33). These pathways have obvious biological and physiological importance; their regulation will clearly require further study.

\section{Acknowledgments}

We thank Roland De Soignie for able technical assistance and Nancy Cook for secretarial support.

This work was supported, in part, by the American Gastroenterological Association-Marion Scholarship, and grants R01-DK3519301A1 and P01-AM37260-01 from the National Institutes of Health.

\section{References}

1. Sellin, J. H., and R. De Soignie. 1984. Rabbit proximal colon: a distinct transport epithelium. Am. J. Physiol. 246:G603-G610. 
2. Snipes, R. L., W. Clauss, A. Weber, and H. Hoinicke. 1982. Structural and functional differences in various divisions of the rabbit colon. Cell Tissue Res. 225:331-346.

3. Fromm, M., and U. Hegel. 1978. Segmental heterogeneity of epithelial transport in rat large intestine. Pfluegers Arch. Eur. J. Physiol. 378:71-83.

4. Clauss, W., H. Schafer, I. Horch, and H. Hoinicke. 1985. Segmental differences in electrical properties and Na-transport of rabbit cecum, proximal and distal colon in vitro. Pfluegers Arch. Eur. J. Physiol. 403:278-282.

5. Sullivan, S. K., and P. L. Smith. 1986. Bicarbonate secretion by rabbit proximal colon. Am. J. Physiol. 251:436-445.

6. Donowitz, M., and H. J. Binder. 1976. Effect of enterotoxins of Vibrio cholerae, Escherichia coli and Schigella dysenteriae type 1 on fluid and electrolyte transport in the colon. J. Infect. Dis. 134:135-143.

7. Cragoe, E. J., O. N. Wotersdorf, Jr., J. B. Bicking, S. F. Kwong, and J. H. Jones. 1967. Pyrazine diuretics. II. $N$-Amidino-3-amino-5substituted-6-Halopyrazine carboxamides. J. Med. Chem. 10:66-75.

8. U. S. Patent 4,246,406, January 20, 1981. E. J. Cragoe, O. W. Wotersdorf, Jr., and S. J. deSolms. Heterocyclic Substituted Pirazinoylguanidines.

9. Sellin, J. H., and R. De Soignie. 1983. Methylprednisolone increases absorptive capacity of rabbit ileum in vitro. Am. J. Physiol. 245:G562-G567.

10. Frizzell, R. A., M. J. Koch, and S. G. Schultz. 1976. Ion transport by rabbit colon. J. Membr. Biol. 27:297-316.

11. Garvin, J. L., S. A. Simon, E. J. Cragoe, and L. F. Mandel. 1985. Phenamil: an irreversible inhibitor of sodium channels in the toad bladder. J. Membr. Biol. 87:45-54.

12. Benos, D. J., J. L. Mandell, and S. A. Simon. 1980. Effects of chemical group specific reagents on sodium entry and the amiloride binding site in frog skin: evidence of separate sites. J. Membr. Biol. 56:149-158, 1980.

13. Chang, E. B., M. Field, and R. J. Miller. 1982. Adrenergic receptor regulation of ion transport in rabbit ileum. Am. J. Physiol. 242:G237-G242.

14. Sellin, J. H., and R. De Soignie. 1987. Regulation of $\mathrm{Na}-\mathrm{Cl}$ absorption in rabbit proximal colon in vitro. Am. J. Physiol. 252:G45-G51.

15. Sellin, J. H., and R. De Soignie. 1985. Steroids alter ion transport and absorptive capacity in proximal and distal colon. Am. J. Physiol. 249:G113-G119.

16. Will, P. C., R. N. Cortright, R. G. Groseclose, and U. Hopfer. 1985. Amiloride-sensitive salt and fluid absorption in small intestine of sodium-depleted rats. Am. J. Physiol. 248:G133-G141.

17. Loeschke, K., H. Fabritius, and H. F. Walter. 1986. Adaptation of electrolyte transport in rat large intestine after proximal resection. Pfluegers Arch. Eur. J. Physiol. 406:323-327.
18. Turnheim, K., R. A. Frizzell, and S. G. Schultz. 1977. Effect of anions on amiloride-sensitive, active sodium transport across rabbit colon in vitro. J. Membr. Biol. 37:63-84.

19. Heintze, K., K. U. Petersen, and J. R. Wood. 1981. Effects of bicarbonate on fluid and electrolyte transport by guinea pig and rabbit gallbladder: stimulation of absorption. J. Membr. Biol. 62:175-181.

20. Sariban-Sohraby, S., and D. J. Benos. 1986. The amiloridesensitive sodium channel. Am. J. Physiol. 250:C175-C190.

21. Fuchs, W., E. H. Larsen, and B. Lindemann. 1977. Currentvoltage curve of sodium channels and concentration dependence of sodium permeability in frog skin. J. Physiol. (Lond.). 267:137-166.

22. Van Driessche, W., and B. Lindemann. 1979. Concentration dependence of currents through single sodium-selective pores in frog skin. Nature (Lond.). 282:519-520.

23. Garty, H., and I. S. Edelman. 1983. Amiloride-sensitive trypsinization of apical sodium channels. J. Gen. Physiol. 81:785-803.

24. Sariban-Sohraby, S., M. Burg, W. P. Wiesman, P. K. Chiang, and J. P. Johnson. 1984. Methylation increases sodium transport into A6 apical membrane vesicles: possible mode of aldosterone action. Science (Wash. DC). 225:745-746.

25. Gottlieb, G. P., K. Turnheim, R. A. Frizzell, and S. G. Schultz. 1979. P-chloromeicuribenzine blocks and reverses the effect of amiloride on sodium transport across rabbit colon in vitro. Biophys. $J$. 401:125-129.

26. Li, J. H-Y, and B. Lindemann. 1983. Chemical stimulation of $\mathrm{Na}$ transport through amiloride-blockable channels of frog skin epithelium. J. Membr. Biol. 75:179-192.

27. Lewis, S. A., and N. K. Wills. 1983. Apical membrane permeability and kinetic properties of the sodium pump in rabbit urinary bladder. J. Physiol. (Lond.). 341:169-184.

28. Thompson, S. M., and J. H. Sellin. 1986. Relationships among sodium current, permeability and $\mathrm{Na}$ activities in control and glucocorticoid-stimulated rabbit descending colon. J. Membr. Biol. 92:121-134.

29. Leng-Peschlow, E., and J. Marty. 1979. Absorption of water, electrolytes and volatile fatty acids in the rabbit caecal pouch. J. Comp. Physiol. 133:205-210.

30. Smith, P. L., M. A. Cascairo, and S. K. Sullivan. 1985. Sodium dependence of luminal alkalinization by rabbit ileal mucosa. Am. J. Physiol. 249:G358-G368.

31. Rao, M. C., S. Guandalini, P. L. Smith, and M. Field. 1980. Mode of action of heat stable escherichia coli enterotoxin. Biochim. Biophys. Acta. 632:35-46.

32. Sellin, J. H., and M. Field. 1981. Physiologic and pharmacologic effects of glucocorticoids on ion transport pharmacologic effects of glucocorticoids on ion transport across rabbit ileal mucosa in vitro. J. Clin. Invest. 67:770-778.

33. Sellin, J. H., and R. De Soignie. 1987. Ion transport in human colon in vitro. Gastroenterology. 93:441-448. 